\title{
Editorials
}

\section{How can medical schools encourage students to choose general practice as a career?}

\section{BACKGROUND}

The NHS faces a continuing rise in volume and complexity of population health needs, with care moving increasingly from hospital to community. National reviews of medical training and workforce requirements report a critical need for an increase in the NHS GP workforce, and NHS England has now responded with a welcome promise of investment in primary care. ${ }^{1}$ This may provide funding for GPs, but where will these GPs come from? Medical schools and the Royal College of General Practitioners are working to promote general practice as a career, but the current uptake of GP training is disappointing, with only $17.4 \%$ of F2 doctors appointed to GP training in the UK in 2015.2 Health Education England's GP training recruitment targets for 2016 are likely to be missed.

Many questions must be asked. What explains the wide variations across medical schools in graduates' choice of general practice as a career (range 7.3-30.0\%)? ${ }^{2}$ Is there a cultural bias against primary care in medical schools? How important is the quantity and quality of undergraduate general practice exposure? Are we taking the wrong approach to selection processes in order to meet the needs of contemporary society?

\section{ADEQUATE FUNDING AND SUPPORT OF STUDENT PLACEMENTS IN GENERAL PRACTICE}

Undergraduate experience has a major influence on career choice. Evidence from the UK and abroad shows that undergraduate exposure to general practice has a positive influence on students considering general practice as a career. ${ }^{3}$ Yet, following a steady increase over the past 20 years, the percentage of teaching in general practice in UK medical schools has plateaued Imean $13 \%$ ) since 2008 and the average amount of clinical contact in general practice settings has decreased overall. ${ }^{4}$

Capacity for undergraduate general practice placements is now a serious challenge for many medical schools with practices facing competing demands from service and expansion of postgraduate training activity. Postgraduate trainees are often viewed as 'better value' in terms of service, causing some practices to choose postgraduate training over undergraduate teaching.
Medical students' perception of their GP teachers' job satisfaction positively affects their wish to become GPs. ${ }^{5}$ Although many aspects of GP job satisfaction are beyond the remit of medical schools, they can at least ensure that GP teachers are properly supported. An optional teaching qualification could open up a career path into academia for experienced GPs. Funding is crucial. Undergraduate teaching payments no longer reflect the cost of re-providing service lost from teaching and are consistently lower than those made to secondary care providers of undergraduate placements. ${ }^{6}$ Yet general practice teaching has been shown to be as effective as, if not better than, hospital teaching when it is adequately resourced.?

\section{THE GENERAL PRACTICE FORWARD VIEW}

The General Practice Forward View published by NHS England in April 2016 provides welcome recognition of the need to improve the medical school experience of general practice through greater community exposure and the encouragement of students to make a positive choice of general practice as a career. ' Detailed recommendations are also included in the Fourth Report of the House of Commons Health Committee published on the same day. ${ }^{8}$ Medical schools must now recognise the educational value of teaching based in primary care, moving students and resources from the hospital setting whenever learning could take place equally or more appropriately in the community. Funding streams must adapt accordingly.

\section{GENERAL PRACTICE NEEDS TO BE CHAMPIONED WITHIN THE UNDERGRADUATE CURRICULUM}

Undergraduate medical curricula must respond to changing health patterns and the need for expert generalists in the modern healthcare workforce. Greater emphasis has to be placed on the management of long-term conditions and the challenges arising from an ageing population with multiple morbidities.

Academic GPs must be seen and heard in prominent and senior roles within medical schools, both in teaching and research. Despite GPs comprising 27.5\% of the total medical workforce, the UK's academic GPs account for only $6.2 \%$ of all clinical academics. ${ }^{9}$ Students need to know the extent and importance of primary care research and how this informs teaching and practice.

There should be increased input from general practice at all stages of medical school activities, including selection panels, community placements, campusbased teaching, student support services, and, crucially, assessment. Examinations at all stages should reflect more closely medical needs encountered in community care settings. Recruitment materials need to reflect the full range of graduate opportunities rather than depicting images predominantly of high-tech specialties.

Growing evidence from the UK and from international studies on Longitudinal Integrated Clerkships (LICs) suggests that longer, more immersive community placements make students more likely to choose general practice as a career, ${ }^{10}$ as well as producing more empathic, work ready' students. It may be time to replace frequent specialty rotations with more immersive placements.

Research suggests that some students opt for hospital careers believing they offer greater intellectual challenge than general practice. ${ }^{11}$ If we wish to counter this view we must provide undergraduate primary care exposure that challenges students, testing not only their communication skills but also their clinical reasoning, diagnostic, ethical, and management competences. General practice is an ideal setting in which to learn about clinical leadership and quality improvement. Innovative community modules such as managing complexity, community prescribing, and medication monitoring can allow students to experience this breadth.

Widening participation projects may indirectly help GP recruitment as UK GP trainees are more likely to have state education than other specialties. ${ }^{12}$ Creative options such as part-time training in early years combined with paid work as a receptionist or healthcare assistant in a GP practice could widen participation while incorporating elements of LICs, especially if students returned to the same practice for attachments.

In 2015 only $35 \%$ of medical students described their medical school as supportive of general practice as a career, with many comments on negative attitudes to general 
practice. Research suggests that negative comments about general practice as a career choice (by both GPs and specialists) are prevalent and have an influence on student career choice. ${ }^{13}$

Medical schools could and should do more to expose students to GP teachers as important role models and valued members of faculty, and provide greater encouragement and support for student GP societies. These can also help students consider work-life balance questions, which have been shown to be an important determinant in choice of career for 'Generation Y' doctors.

\section{FURTHER EVIDENCE NEEDED}

Considering the anticipated crisis in the GP workforce and its serious implications for the NHS, the relative lack of emphasis on research in this area is a cause for concern. Evidence is urgently needed to help us understand how primary care can best contribute to undergraduate education and how this affects students' career choice and approach to practising medicine in the broadest sense.

Further questions remain: How do the negative attitudes towards general practice as a career affect students' career intentions? Is this in fact a discriminatory issue and does ethical behaviour by medical teachers need to be addressed? The Athena Swan initiative is currently supporting and advancing women's careers in medical education and research. Do we need a similar programme for GPs?

\section{CONCLUSION}

Career choice within medicine is a complex phenomenon combining personal and social influences. Preferences may change at different stages of life and of training, but there is no doubt that undergraduate experience has a strong influence on eventual career choice.

\section{ADDRESS FOR CORRESPONDENCE}

\section{Paula McDonald}

Department of Primary Care and Public Health,

Brighton and Sussex Medical School, Mayfield

House, Falmer Campus, Brighton BN1 9PH, UK.

\section{E-mail: P.Mcdonaldabsms.ac.uk}

If the UK is to continue to have a strong GP workforce within a dynamic and internationally regarded primary care service, then medical schools must urgently implement change. Box 1 summarises the key actions that we believe are now necessary. As GP educators we strongly support the recommendations of the House of Commons Health Committee in relation to undergraduate medical education. The most pressing of these is to move, by the start of academic year 2016-2017, to a payment mechanism that reflects the true cost to GP practices of teaching medical students. This will surely be a critical step towards ensuring a viable NHS primary care workforce for the future.

\section{Paula McDonald,}

Senior Teaching Fellow, Department of Primary Care and Public Health, Brighton and Sussex Medical School, Brighton.

\section{Ben Jackson,}

Senior Clinical Teacher in Primary Medical Care, Academic Unit of Primary Medical Care, University of Sheffield, Sheffield.

\section{Hugh Alberti,}

Sub-Dean for Primary and Community Care, School of Medical Education, The Medical School, Newcastle University, Newcastle.

\section{Joe Rosenthal,}

Senior Lecturer in General Practice and Sub-Dean for Community Based Teaching, Department of Primary Care and Population Health, University College London, London.

\section{Provenance}

Freely submitted; externally peer reviewed.

\section{Box 1. Actions urgently required to increase uptake of general practice as a career}

\section{Increase}

- Quantity of undergraduate teaching in general practice

- The proportion of exam questions that are set in primary and community settings

- The proportion of academic GPs and students' exposure to them

- Funding for undergraduate placements in general practice

- Research into career influences of medical students

\section{Review}

- The extent that general practice is denigrated in medical school culture, and if necessary confront the phenomenon as a discriminatory issue

- How medical students are recruited and selected

- The career structure and pathways for GPs interested in undergraduate medical education or clinical research

\section{Online first}

This article was published online first on 10 May 2016.

DOI: 10.3399/bjgp16X685297

\section{REFERENCES}

1. NHS England. General practice forward view. 2016. https://www.england.nhs.uk/wp-content/ uploads/2016/04/gpfv.pdf laccessed $27 \mathrm{Apr}$ 2016).

2. UK Foundation Programme Office. F2 career destination report 2015. http:// www.foundationprogramme.nhs.uk/ download.asp?file=F2_Career_Destination Report_2015___FINAL.pdf laccessed 27 Apr 2016).

3. Howe A, Ives G. Does community-based experience alter career preference? New evidence from a prospective longitudinal cohort study of undergraduate medical students. Med Educ 2001; 35(4): 391-397.

4. Harding A, Rosenthal J, Al-Seaidy M, et al. Provision of medical student teaching in UK general practices: a cross-sectional questionnaire study. Br J Gen Pract 2015; DOI: 10.3399/bjgp15X685321.

5. Meli D, Ng A, Singer S, et al. General practitioner teachers' job satisfaction and their medical students' wish to join the field $-\mathrm{a}$ correlational study. BMC Fam Pract 2014; 15(1): 50.

6. Harding A, McKinley R, Rosenthal J, Al-Seaidy $M$. Funding the teaching of medical students in general practice: a formula for the future? Educ Prim Care 2015; 26(4): 215-219.

7. Park S, Khan N, Hampshire M, et al. A BEME systematic review of UK undergraduate medical education in the general practice setting. BEME Guide 32. Med Teach 2015; 6: 1-20. [Epub ahead of print].

8. House of Commons Health Committee. Primary care: fourth report of session 2015-2016. 2016. http://www.publications.parliament.uk/pa/ cm201516/cmselect/cmhealth/408/408.pdf (accessed 27 Apr 2016).

9. Centre for Workforce Intelligence. In-depth review of the general practitioner workforce. Final report. 2014. http://www.cfwi.org.uk/ publications/in-depth-review-of-the-gpworkforce/attachment.pdf laccessed $28 \mathrm{Apr}$ 2016).

10. Walters L, Greenhill J, Richards J, et al. Outcomes of longitudinal integrated clinical placements for students, clinicians and society. Med Educ 2012; 46(11): 1028-1041.

11. Cleland JA, Johnston PW, Anthony M, et al. A survey of factors influencing career preference in new-entrant and exiting medical students from four UK medical schools. BMC Med Educ 2014; 14(1): 1

12. Rodríguez Santana I, Chalkley MJ. The socioeconomic and demographic characteristics of United Kingdom junior doctors in training across specialities. (CHE Research Paper; 119). 2015. http://www.york.ac.uk/media/ che/documents/papers/researchpapers/ CHERP_119_junior_doctors_training specialities.pdf (accessed 27 Apr 2015).

13. Ajaz A, Rhodri D, Brown D, Smuk M. BASH: badmouthing, attitudes and stigmatisation in health care as experienced by medical students BJPsych Bull 2016; 40(2): 97-102. 